\title{
Reinhart Koselleck y la temporalidad histórica*
}

\author{
Elías J. Palti
}

Universidad de Buenos Aires / Universidad Nacional de Quilmes / CONICET

$\mathrm{E}$ 1 nombre de Reinhart Koselleck (Görlitz, 1923-Bad Oeynhausen, 2006) se encuentra hoy asociado de manera estrecha con la llamada escuela alemana de "historia de conceptos" (Begriffsgeschichte), la cual tuvo sus inicios a fines de la década del '60 junto con sus maestros, Otto Brunner y Werner Conze. Esta escuela se orientó, básicamente, a trazar la historia de diversos conceptos y de cómo su uso y su significado se alteró a través de los tiempos, proyecto que cristaliza en tres grandes diccionarios: Geschichtliche Grundbegriffe. Historisches Lexikon zur Politische-sozialen Sprache in Deutschland [Conceptos básicos de historia. Un Diccionario sobre los principios del lenguaje político-social en Alemania (Stuttgart, 1972-1997)], Historisches Wörterbuch der Philosophie [Diccionario de filosofía de principios históricos (Basilea, 1971-2007)] y Handbuch politisch-sozialer Grundbegriffe in Frankreich, 1680-1820 [Manual de conceptos político-sociales en Francia, 1680-1820 (Munich, 1985)].

El primero de ellos, Geschichtliche Grundbegriffe, es hoy un texto de referencia clave para los historiadores, lo que hizo de Koselleck uno de los autores más influyentes en el campo. Se trata de una obra verdaderamente monumental, que llevó varias décadas de elaboración e involucró a un gran número de investigadores. Paradójicamente, Koselleck no se destacó por escribir, él mismo, obras de largo aliento. ${ }^{1}$ Tiene, en cambio, una vasta producción de artículos, que han sido reunidos en diversas antologías, varias de ellas traducidas, de manera parcial, a nuestro idioma. La más extensa es el libro Zeitschichten (estratos del tiempo), que era parte de un proyecto editorial más amplio que quedó inconcluso y al que el texto que aquí se reproduce sirvió como introducción.

Como indica ya el título del libro, el tema central que recorre la serie de escritos allí reunidos es el análisis de las estructuras de la temporalidad. ${ }^{2}$ No se trata, pues, de un estudio de historia conceptual; en rigor, ni siquiera es un texto histórico, aunque en él apele a ejemplos históricos, sino metahistórico, de teoría histórica. En efecto, en sus escritos más recientes sus

\footnotetext{
* La presente sección, “Argumentos”, ha sido organizada especialmente para Prismas por Lucila Svampa, Daniela Losiglio y Elías Palti. El texto de Koselleck fue traducido por Martín Rodríguez Baigorria, con fondos del PICT 2017 1656, titulado: "Actualidad del pasado. Búsquedas y obstáculos a través de las perspectivas de Walter Benjamin y Reinhart Koselleck".

${ }^{1}$ La obra más extensa y sistemática que escribió fue su tesis de habilitación, Preussen zwischen Reform und Revolution: Allgemeines Landrecht, Verwaltung und soziale Bewegung von 1791 bis 1848, Stuttgart, Ernst Klett Verlag, 1967. ${ }^{2}$ Reinhart Koselleck, Zeitschichten, Frankfurt am Main, Suhrkamp Verlag, 2000.
} 
preocupaciones históricas, o histórico-conceptuales, fueron cediendo terreno al proyecto de comprender cuál es la naturaleza del tiempo histórico, algo que, digamos, genera ya algunas tensiones respecto de su proyecto original. En principio, un historiador conceptual no se propondría definir qué es la historia, qué es el tiempo, etc., sino, más simplemente, comprender cómo han sido concebidos tales conceptos por los distintos autores y en los diversos momentos o períodos, sin pretender dictaminar al respecto (no afirma que "la historia es tal o cual cosa", sino, más humildemente, señala que "para tal o cual autor, la historia es tal o cual cosa").

De hecho, habría cierta incompatibilidad entre ambos enfoques. Según asegura la expresión de Nietzsche que Koselleck adoptó como una suerte de máxima, "solo lo que no tiene historia es definible". ${ }^{3}$ Como sostenía en los textos compilados en Futuro Pasado, lo que define a los conceptos, y los distingue de las "ideas", es su mutabilidad, por lo que resultan siempre plurívocos, indefinibles. Intentar proveer a los mismos una definición unívoca supondría así violentar su historicidad, fijarlos en un momento dado en el cual, presumiblemente, se encontraría finalmente plasmado su "auténtico" sentido. En última instancia, para Koselleck pretender determinar cuál es la "verdadera" entre la variedad de definiciones que cobró históricamente cierto concepto significaría una intromisión ilegítima de la subjetividad del historiador en cuestión, indicaría, simplemente, que es la que coincide con su propia idea del mismo, lo que no viene al caso para una historia conceptual. En fin, obliga a allanar su trayectoria efectiva para reducir todas las definiciones alternativas surgidas históricamente a meros anticipos más o menos deficientes respecto de aquella a la que, en cada caso, se adhiere.

Sin embargo, ya en sus escritos tempranos Koselleck insiste, al mismo tiempo, en la necesidad de una teoría que sirva de guía para la comprensión histórica, una "anticipación teórica", según la llama, esto es, una cierta idea respecto de qué es la historia, qué es el tiempo histórico, etc. ${ }^{4}$ Esto dará lugar a lo que se convertirá en su preocupación central: la elaboración de una Historik, que define como una "doctrina de las condiciones de posibilidad de historias (Geschichten)". 5 Así, en sus trabajos más recientes, Koselleck intenta desarrollar una teoría general de las formas de la experiencia histórica. Estas ya no se relacionarán con ninguna época singular, sino con las condiciones a priori de la inteligibilidad histórica; remiten, por lo tanto, para él, al plano de las determinaciones antropológicas y, en última instancia, biológicas.

Como afirma en uno de los textos incluidos en Zeitschichten, "Erfahrungswandel und Methodenswechsel. Eine historisch-anthropologische Skizze" ["Mutación de la experiencia y cambio de método. Un esbozo histórico-antropológico" (1988)], "de lo que se trata es de descubrir las condiciones antropológicas de todas las experiencias posibles". ${ }^{6}$ Este enfoque antropológico-filosófico le permite definir tres metodologías históricas fundamentales, encarnadas

\footnotetext{
${ }^{3}$ Friedrich Nietzsche, Sobre la genealogía de la moral, cap. II, §13.

${ }^{4} \mathrm{Al}$ respecto resulta ilustrativo el texto, que aparece el mismo año de lanzamiento del $G G$ (1972), "Sobre la necesidad de la teoría de la ciencia histórica". Véase Reinhart Koselleck, "Über die Theoriebedürftigkeit der Geschichtswissenschaft", en Werner Conze (ed.), Theorie der Geschichtswissenschaft und Praxis der Geschichtsunterrichts, Stuttgart, Klett-Cotta, 1972, pp. 10-28. Este texto se incluye en una antología de textos de Koselleck preparada por Claudio Ingerflom y Elías Palti, de próxima aparición en FCE de Argentina, y cuyo título es Sobre el concepto de Estado y otros ensayos de teoría histórica.

${ }^{5}$ Koselleck, "Historia y hermenéutica", en Koselleck y H.-G. Gadamer, Historia y hermenéutica, Barcelona, Paidós, 1997, p. 70.

${ }^{6}$ Koselleck, "Erfahrungswandel und Methodenswechsel. Eine historisch-anthropologische Skizze", en Zeitschichten, Frankfurt am Main, Suhrkamp Verlag, 2000), p. 33.
} 
respectivamente en Heródoto, Polibio y Tucídides, y que se repiten en los más diversos contextos históricos y conceptuales. Cada una de ellas nace -afirma- de las diversas formas humanas posibles de relacionarse con las estructuras de la temporalidad, que hunden sus raíces en condiciones radicadas en un nivel biológico de la especie y expresan, a su vez, tres modos diferenciales de adquisición (y pérdida) de conocimiento ("nuestro ensayo - dice- se aferra siempre a las características formales comunes que bien podrían ser el fundamento de todas las experiencias y de sus enriquecimientos, de todos los métodos y de sus desarrollos diferenciales").

En este punto, Koselleck retoma la categorización tripartita elaborada por Braudel entre corto, mediano y largo plazo, buscando sus fundamentos antropológicos últimos. "Los ritmos de la experiencia específica a las generaciones", asegura, resultan de ciertos "datos biológicos iniciales." ${ }^{\text {E }}$ El corto plazo expresa un modo inmediato de experimentar la sucesión de los acontecimientos, propia de los contemporáneos, en su singularidad e irrepetibilidad. El mediano plazo se liga a la experiencia generacional que permite descubrir patrones y recurrencias entre fenómenos diversos determinados por condiciones estructurales más o menos estables en el tiempo. Solo aquí, cuando referimos los acontecimientos a secuencias evolutivas de más largo alcance, podemos hablar de un proceso de aprendizaje o ganancia de experiencia. El largo plazo, finalmente, remite a las formas intergeneracionales de adquisición de conocimiento, pero también de pérdida del mismo, que permite observar cómo las propias condiciones estructurales, a su vez, se modifican. Estos procesos históricos de largo alcance escapan ya al ámbito de la experiencia inmediata y solo pueden descubrirse mediante un esfuerzo de abstracción intelectual.

Como vemos, llegado a este punto, Koselleck se interna en el plano de los aprioris que hacen posible la comprensión histórica, indagando en las diversas formas de la experiencia de la temporalidad. No es tampoco exactamente a esto, sin embargo, a lo que apunta en el texto que se presenta aquí. En él Koselleck se refiere a estructuras de la temporalidad que son objetivas, que no remiten a las formas de la conciencia sino a la estructura de los propios sistemas de interacciones sociales.

Su postura al respecto, por otro lado, supone una suerte de rebelión contra aquellos enfoques centrados en la mutabilidad conceptual, lo que significa un giro importante en su pensamiento. ${ }^{9}$ Según afirma ahora, toda interacción social presupone cierta estabilidad significativa que permita la repetibilidad del sentido. Retoma aquí la distinción entre langue y parole de Saussure. Frente al carácter acontecimiental de los usos del lenguaje, que los hace siempre únicos e irrepetibles, las estructuras lingüísticas estabilizan el orden de los sentidos, asegurando así su comunicabilidad y transmisibilidad. Koselleck apela en este punto a la idea de Arnold Gehlen, muy cara a todo el pensamiento neokantiano, de "institución". ${ }^{10}$ Las estructuras del lenguaje participan, pues, de una temporalidad distinta a la del corto plazo de la pragmática lingüística. En última instancia, todo uso, todo acontecimiento lingüístico, es parasitario de los universos semánticos; aun cuando sea para rebelarse contra ellos, siempre los

\footnotetext{
${ }^{7}$ Ibid.

${ }^{8}$ Koselleck, "Erfahrungswandel und Methodenswechsel", en Zeitschichten, p. 35.

${ }^{9}$ Visto desde otra perspectiva, tal giro no sería realmente tal, sino que recoge una preocupación suya de larga data, como es su rechazo de las visiones lineales del tiempo histórico, con su carga de utopismo, rechazo que, en última instancia, denuncia cierta vena antimoderna.

${ }^{10}$ En Urmensch und Spärkultur (1956), Gehlen introduce el término tomando su sentido de su raíz etimológica, es decir, como "costumbre" (institutio) o conductas e ideas habituales, adoptadas acríticamente.
} 
presupone. Esto no quiere decir que las estructuras conceptuales sean realidades eternas, que no se alteren con el tiempo, pero esta temporalidad operaría con mayor morosidad, proyectándose sobre el mediano y el largo plazo. Y tampoco sus ritmos son uniformes, sino que, en este plano, habrán de superponerse siempre estratos diversos de temporalidad cuyos coeficientes de variabilidad relativos nunca, o no necesariamente, coinciden.

Con el concepto de "estratos del tiempo" pasamos así, subrepticiamente, del orden de los a prioris de la comprensión histórica al de sus a posteriori, a las estructuras objetivas de la temporalidad que se encuentran inscriptas en los sistemas de interacción humana, y que se descubren como resultado del propio estudio de la historia, pero que funcionarían, a la vez, como un a priori, como esa "anticipación teórica" que hace posible un relato histórico, es decir, abre el espacio a un determinado horizonte de comprensión de la historia. Esta ambigüedad, esta oscilación entre lo a priori y lo a posteriori, que surge en el momento mismo en que se intenta reflexionar acerca de aquello que constituye la categoría histórica fundamental, que es la del tiempo, nos enfrenta a aquella problemática clave de la disciplina, que refiere a su estatuto epistemológico, cómo establecerlo y, en definitiva, a su impasibilidad última, que es lo que abre, justamente, el espacio para las disputas que se suscitarán de manera recurrente en torno del mismo. En última instancia, este triple impasse (la oscilación entre lo a priori y lo a posteriori, entre las formas de conciencia histórica y las estructuras objetivas de la temporalidad, y, finalmente, entre la historia y la meta historia, que resulta de la simultánea necesidad e imposibilidad de definiciones unívocas) no expresarían meras divergencias subjetivas, opiniones, sino que pondrían de manifiesto cierta inconsistencia inherente al propio campo, esto es, esa circularidad lógica que se establece, de manera inevitable, entre la anticipación teórica y los productos de la investigación histórica.

Koselleck no ofrece aquí una respuesta, cuya búsqueda lo habría encerrado en una tarea siempre ímproba, y, en última instancia, inconducente. Pero sus reflexiones nos ofrecen, en cambio, la posibilidad de observar y analizar la serie de problemas que la cuestión de la temporalidad histórica plantea a los historiadores. Problemas, en última instancia, insolubles, pero, al mismo tiempo, ineludibles. De hecho, toda narrativa histórica presupone ya una cierta respuesta a los mismos; en definitiva, a todas ellas subyace un concepto implícito de la temporalidad. Su lectura nos permite, en fin, tratar de hacer consciente la serie de cuestiones de índole epistemológica que se despliegan en torno de la misma.

Los comentarios que siguen al texto de Koselleck de Lucila Svampa y Faustino Oncina Coves explican y desarrollan el planteo koselleckiano situándolo en el marco de su proyecto histórico-conceptual más general, cómo se sitúa el mismo dentro de su teoría y el lugar que ocupa en su obra. En ellos el lector podrá encontrar una exposición de la amplia gama de aspectos involucrados en la cuestión de la temporalidad, como la naturaleza metafórica de las referencias al tiempo, la relación entre tiempo y espacio, entre el tiempo histórico y los ciclos naturales, el vínculo entre las ideas de estratos de temporalidad y simultaneidad de lo no-contemporáneo, su oposición, a su vez, a la idea de la linealidad del tiempo, etc. Ellos nos permiten comprender así el sentido más profundo que adquiere en Koselleck la figura de "estratos del tiempo", y también las razones de la centralidad que cobra esta en sus trabajos más recientes, convirtiéndose en el núcleo de su proyecto de una Historik. 